\title{
Hegemony in Film: How Holocaust is Legitimized through Visual and Linguistic Texts?
}

\author{
Riskia Setiarini, Universitas Jember
}

\begin{abstract}
Within the late of 1980s to the early 1990s, a myriad of films containing Holocaust were produced. One of which was Schindlers' List. The depiction of eeriness of holocaust was wrapped in a scantily flawed film, subtly permeated into people's minds. The filmmaker spreads their power, asking for people's consent, not through coercion but through cognition. This is so-called hegemony. Holocaust left us a memory that during those years, Jews suffered severely, not only were expelled from their homey homes, they were also killed in such inhumanely way. Some selected shots with inter title in them were selected as the data. Both the linguistic in the inter title as well as the visual semiotic resources were juxtaposed to uncover the relation, leading to a meaning conceived.
\end{abstract}

Keywords: hegemony; holocaust; legitimization; multimodal discourse analysis; power

\section{Introduction}

I was a teenager when watching Spielberg's Indiana Jones, Rambo, X-Files, and holocaust-themed movies. To me at that time, American stands as a superpower state, it is the resemblance of the depiction of the current modern civilization. From holocaust-themed movies which seemed to be the trend behind all war-themed films produced 1980-1990s, I came to know that holocaust was an ethnic cleansing, a Jews cleansing occurring around world war II and it was Nazi who was one to blame for the mass killings. I did learn that from the film, believed it and considered that as my knowledge. I soon noticed that my knowledge is likely determined by my engagement to the world, to the things surround, to stuffs outside myself. Kress (2010: 174), van Dijk (in Chilton, 2002) once said that knowledge is said to be the banal process of meaning making by individuals in their engagement with the world. The engagement takes place based on our experiences to get in touch with ones surround us, one of which is media. And media, so far, have been very much influenced and, needless to say, developed by American. But then it soon changed when I came to realize that the films I watch are made in America, and American in this way constructed the concept of the film they made. Films as discourses, are not free valued. They are designed on purpose. Tunstall (in Machin \& van Leeuwen 2007: 11) once said, "The media are American". I assume that this saying is due to a fact that films are believed to be dominated by the operation of American hegemony by Artz (2013, Shin \& Gon, 2008). So, to speak, American undeniably has become one dominant class in media and their development. In this way, American has power, power to make meanings.

This social control of American media over those marginal society who consume the film, is permeated in a subtle way into their cognitions. Without coercion, people, including me, accept this knowledge obtained through their engagement with the film as theirs. It is in accordance with what Lacey (1998: 114) state, "It is through the media that the meanings which we use to make sense of our lives are often structured". Such process is named as hegemony. And, the film maker is indeed not a state body, but it is a social movement, fostering the state hegemony. Torfing (in Kperogi, 2011: 324) hegemony can be exercised not just between and within formal state structures but also between and within social movements, classes, professional practices, etc. The following is what is defined as hegemony:

"Hegemony is an extremely powerful tool of social control because the distribution of power in society is often accepted a natural, as, in fact 'common sense' (which, as we know, is not a natural construct). ...the values of the dominant classes become the norm through conventions of representation used by mainstream media”. (Lacey, 1998: 114)

Based on what Lacey defined, some points in hegemony can be found as follows: 
1. powerful tool of social control of 'the dominant class' over 'marginal society'

2. the 'values' $=$ the norms

3. acted $=$ accepted as 'natural'/' common sense'

4. through medium of 'conventions' $=$ 'representation

These altogether work hand in hand through pictures, and the pictures in the films comprise not only visual but linguistic texts as well. As films conceive the interplay of both visual and linguistic elements where all senses of sensory like hearing, sight, taste, touch are involved, multimodal discourse analysis is applied. Multimodal analysis is now widely used and developed. The approach which bases its view on how meaning making is done under the interaction of all semiotic resources (linguistic, images, colors, etc) at once in one context (Kress, 2010 \& O'Halloran, 2004) comes to be the most appropriate analysis. According to Libo in Roehrich (2013: 15), it is said that a multimodal analysis focusing on images in certain situations in corporates text as part of the image.

Through most holocaust-themed films produced, holocaust is shaped in a particular way, helping construct a concept intentionally implanted to the minds of the viewers. This proves how images and texts work side by side under the direction of the film maker. I as one of the viewers may not realize the subtle implantation made use, so that in the end I accept the concept as mine. I was moved to see the selected images together with the sound and the accompanying text and dialogues in the film, which then helped me understand what holocaust is. I considered what I have perceived is one common sense I should take for granted.

What I want to elaborate in the following is how holocaust can be revealed through both visual and linguistic elements used.

There are some films on holocaust produced within 1980-1990s, mostly by Americans or at least produced by other countries but still following 'American system' (Shin \& Gon, 2008), yet only one which was very popular in their era, that is Schindler's List. Produced by an outstanding director, Stephen Spielberg, this film had won several awards. A scantily flawed film supported by highly selective supporting actors with a very qualified music arrangement, this film successfully depicted a strong character of Schindler - A German-descent businessman -who saved and gave the holocaust survivors a shelter and lives. With a documentary-like film, Schindler's List provided us with two types of images: some in black and white (monochrome) images, and the remaining were in color.

\section{Methods}

There are indeed more researches on hegemony in multidisciplinary subjects, such as law, communication, linguistics, etc., yet there are few researches on describing hegemony with multimodality. The previously conducted researches on the same topic, I use them as supporting theories. As multimodality deals much with more than one type of semiotic resources, texts and images are compared and analyzed. There lie some terms related to the film making. Frames, shots, and scenes are among those terms used and I prefer using shots, based on assumption that a shot is part of a scene, to using other terms. This is a multimodal discourse analysis on hegemony description, rather than revelations, with the underlying theories taken are van Leeuwen's, Roehrich's and Kperogi's hegemony (Gramsci's); and supported by Halliday's Systemic Functional Linguistics. From those scenes available, I only take some scenes with intertitle (text printed as images), which are then reduced into only several shots (without Universal Picture's permission). Those selected shots will be broken down into images, text, camera angle and camera distance as well as colors analyses.

Here is Kperogi's excerpt on how hegemony is conducted, based on Gramsci's theory. First of all, hegemony is on the distribution of power of the dominant class over the marginal one (in this case, the filmmaker is the representation of American hegemony as American help assist the funding of the film). The dominant class represents capitalist society (its opponent is socialism) that executes ideological legitimation. In line with this, there is a statement "texts not only represent social practices, they also explain and legitimate (or delegitimate, critique) them" 
(van Leeuwen, 2008: 20). Therefore, hegemony can be undermined through seeing the legitimation-containing texts. And, here are the results.

\section{Discussions}

Hegemony is hidden within language. And the core point in hegemony is lying within its practice, and the practice can be seen through legitimation. Weber (in van Leeuwen, 2008: 105), claimed that language is without doubt the most important vehicle for establishing and cultivating the belief in its legitimacy. There are three types of hegemony of a capitalist society, as said by Gramsci (in Kperogi, 2008): reproduction, negotiation, and ideological legitimation. The latter works on consciousness in values. Hence, the following describes how hegemony is operated in film and how the interplay of linguistic and visual elements which help to shape the meaning.

\subsection{Hegemony reproduced in the availability of reliable sources}

\subsubsection{Hegemony works on its logic-semantics}

Like any other communication system, sources are one thing to be much concerned. Similarly, hegemony deals so much with the notion of how people can accept the shared information in the film. In Schindler's List, the reliable sources are ones the detail the filmmaker made use of. As said by van Leeuwen (2008), "among those categories he mentions, one of which is authorization". It is legitimation by reference to the authority of tradition, custom, law, and/or persons in whom institutional authority of some kind is vested. From the film, I came to know that there are only some types applied. They are: expert and impersonalisation authorities and the authority of tradition.

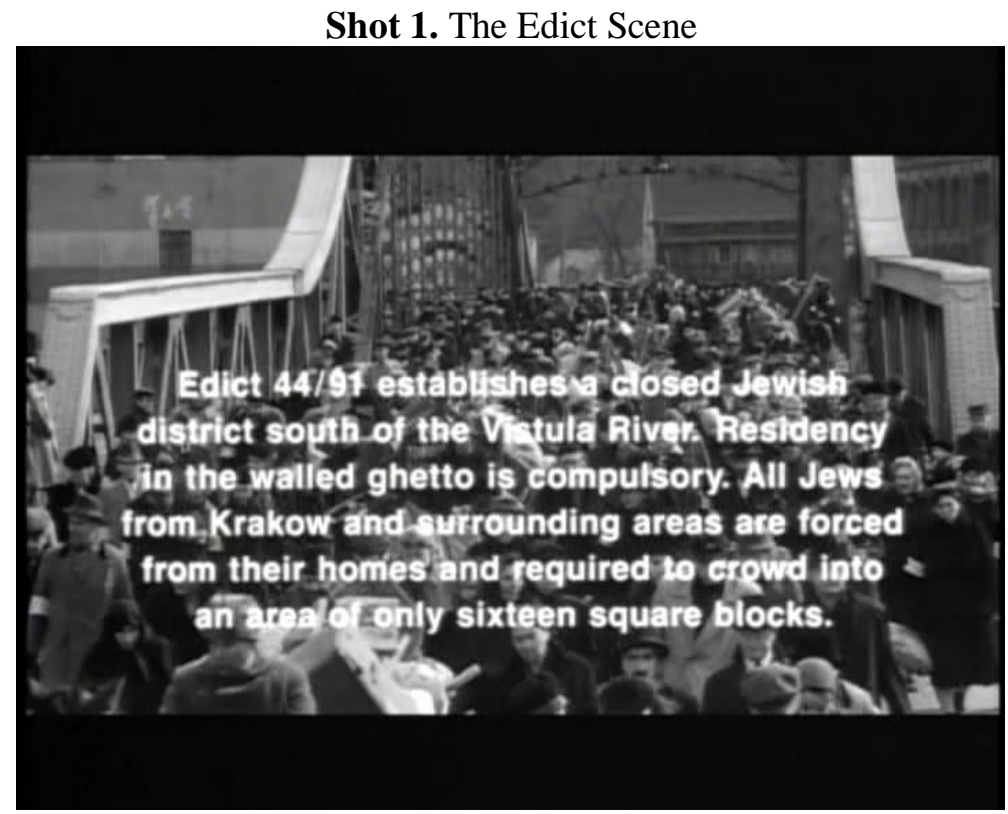

(1) Edict 44/91establishes a closed Jewish District south of the Vistula River. Residency in the walled ghetto is compulsory. All Jews from Krakow and surrounding areas are forced from their homes and required to crowd into an area of only sixteen square blocks. 
Shot 2. The Judenrat Scene

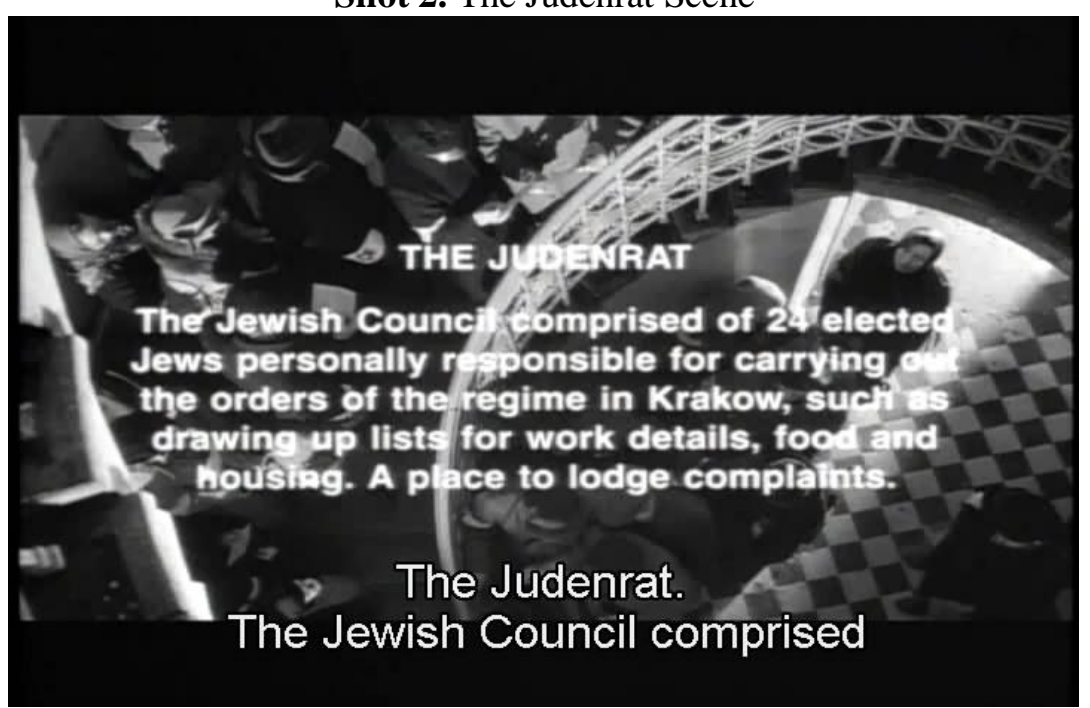

(2)The Judenrat The Jewish Council comprised of 24 elected Jews personally responsible for carrying out the orders of the regime in Krakow, such as drawing up lists for work details, food and housing. A place to lodge complaints.

(3) All Jews from Krakow and surrounding areas are forced from their homes and required to crowd into an area of only sixteen square blocks.

The highlighted text indicates the impersonalisation authority. Van Leeuwen (2008: 108) theorized that "the answer of the question "why" is "because the law (rules, the policies, guidelines) said so". Eventhough van Leeuwen never mentions that impersonal authority is more legitimate than personal or other (role model, expert) authorities, presumably more people share the same opinion that impersonal is more legitimate than personal or even expert authorities. What is convincing is that this impersonal authority does a material process 'establishes' a closed Jewish district south of the Vistula river (goal). Halliday (in Levorato, 2003: 60) stated that this material process signifies that an entity does something to other entity, "the actor (edict 44/91) is the one that does the change" (Halliday \& Matthiessen, 2004: 179).

Another legitimation used is expert legitimation. This type of legitimacy, as explained by van Leeuwen (2008: 107), is provided by expertise rather than status.

"The process used in this intertitle belongs to relational process which serves to characterize and to identify" (Halliday \& Matthiessen, 2004: 210). The notion of this process is closely related to 'being', that the participant has a particular attributive adjective or identification. Here, the Judenrat is defined as a council comprising some members of Jews. "The legitimation categories applied are theoretical rationalization, where rationalization is legitimation by reference to the goals and uses of institutionalized social action and to the knowledges that society has constructed to endow them with cognitive validity" (van Leeuwen, 2008). Rationalization is manufactured through instrumental (effect orientation) and theoretical rationalization (experiential and definition rationalizations). To rationalize an entity, material process is applied as implied in 'are forced' and 'to crowd'; effect rationalization is realized in 'to crowd into ...' and experiential rationalization is given to express 'All Jews ...from Krakow and surrounding areas are forced from their homes and required'. This indicates concrete actions'. The Judenrat part is applying definition rationalization.

\subsubsection{Hegemony works on the interplay of multimodes}

The intertitle is supported by the image of flocks of people (Jews) crossing over the bridge with the intertile in the middle of the frame. "The camera angle used is high level which means that viewer has power into representation" (van Leeuwen, 2008: 139) and it can also indicate the importance of the subject, or the subject is described as weak or inferior, and thus can 
create fatality by Chandler (in Setiarini, 2012: 34). The camera distance is Extreme Long Shot, while Chandler theorized that this can mean to emphasize the background, where this took place, and this also sets the atmosphere of the film. The black and white (monochrome) color (mostly implemented colors in this film), based on my observation, signify the documentary-like, constructing classic style, distinctive compared to other films (as the film was produced in the multicolor era) and can symbolize the noir of the film. This overall can create thrill, and when combines with multicolored, can make cinematic magic (theguardian.com). The logico-semantic of this visual element is proved to be elaboration: clarification. This is due to the meaning shaped which is visually illustrating. The intertitle is put in the middle as salience, the center of attention. When the filmmaker showed us that edict 44/91 forced the Jews to leave their homes and isolated them in a small area set for them, the images illustrated how the flocks of Jews together with their families bringing luggage walking across the places into another. This can build a mental picture on the minds of the viewers. Meanwhile, the Judenrat shot shows elaboration: exposition This is because Judenrat is Jews council with particular authorities but the image representing does not convey the intertitle earnestly. "The shot presents a news means of interpretation" (Roehrich: 2013). Instead of presenting of how Judenratreally did their deeds, this only describes a large number of people going up the stairs in turn, they were in a well-designed building, pretty luxurious and this looks like a house for people's representatives. Elaboration $(=)$ network functions as restating, details, exemplifies or comments

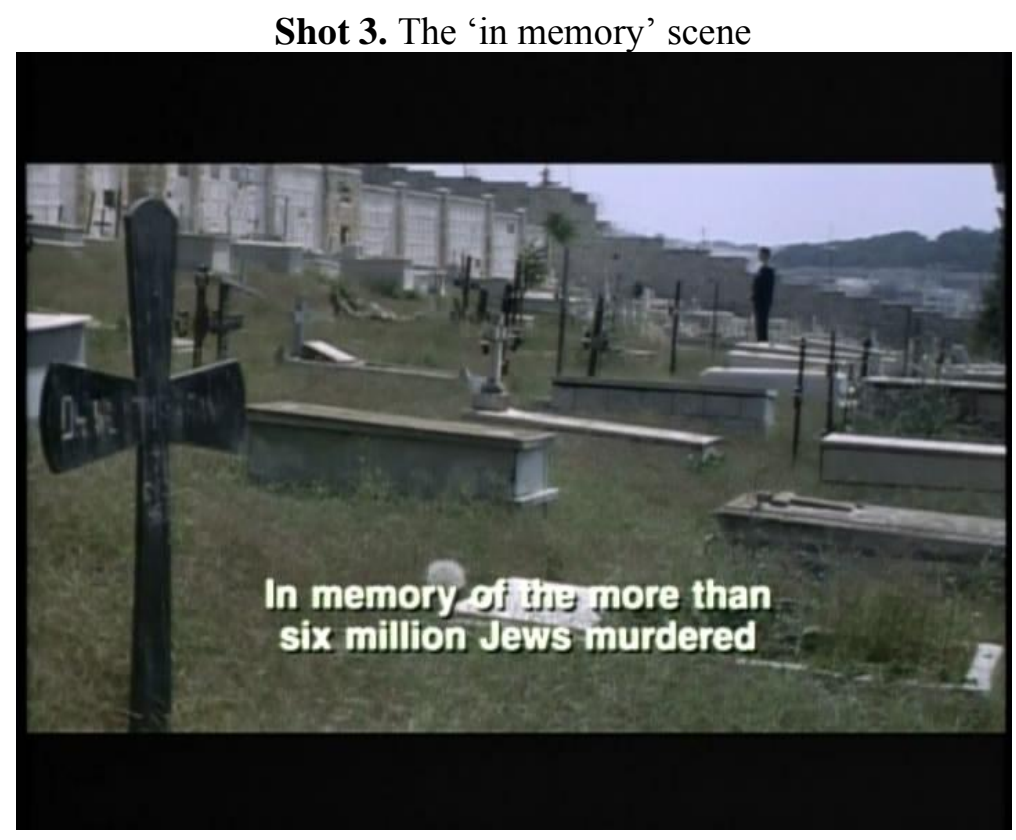

(4) In memory of the more than six million Jews murdered

\subsubsection{Hegemony works on the linguistic elements}

The authority of tradition is said to carry enough weight. Van Leeuwen positioned its importance on the notion "because this is what we always do". Tradition, I may say, is one reason people are encouraged to do the same actions based on the prevailing precedents. In the case of "in memory of the more than six million Jews murdered", this indeed implied that the tragedy killing more than six million of Jew happened in the past and 'in memory' implies a proposition that we ever once reminisce this as an unforgettable memory that likely is commemorated in a period of time. "The process used is existential process referring to a notion that something exists or happens" (Halliday \& Matthiessen, 2004: 256). 


\subsubsection{Hegemony works on the interplay of the multimodes}

The image shown is a cemetery where Schindler was buried, while he is a Christian, and so is the cemetery. The text is 'in memory of the more than six million Jews murdered'. When juxtaposed, these two modes are not closely related, they are not compatible. Because of this, the image is likely restating the text but in different terms. This is so-called elaboration: exposition. The intertitle is at the bottom, Chandler (2002: 88, in Kress \& van Leeuwen, 2006) theorized that this shows reality. The camera angle is eye level, indicating reality and the distance is extreme long shot which shows the background. The multicolor is applied to show the current time.

\subsection{Hegemony reproduced in the availability of concrete quality of objects}

\subsubsection{Hegemony works on the linguistic elements}

When sources are trustworthy, content of the information given will later be put into considerations. Van Leeuwen (2008: 110) explicated that "moral evaluations which deal with adjectives contain both concrete qualities of actions or objects, while this moral evaluation concerns with evaluative adjectives, in particular to attribute, to practice reference".

There some linguistic entities conceiving moral evaluation, in particular what van Leeuwen called 'naturalization' legitimation are found. This is achieved through reference to time and the concept of change.

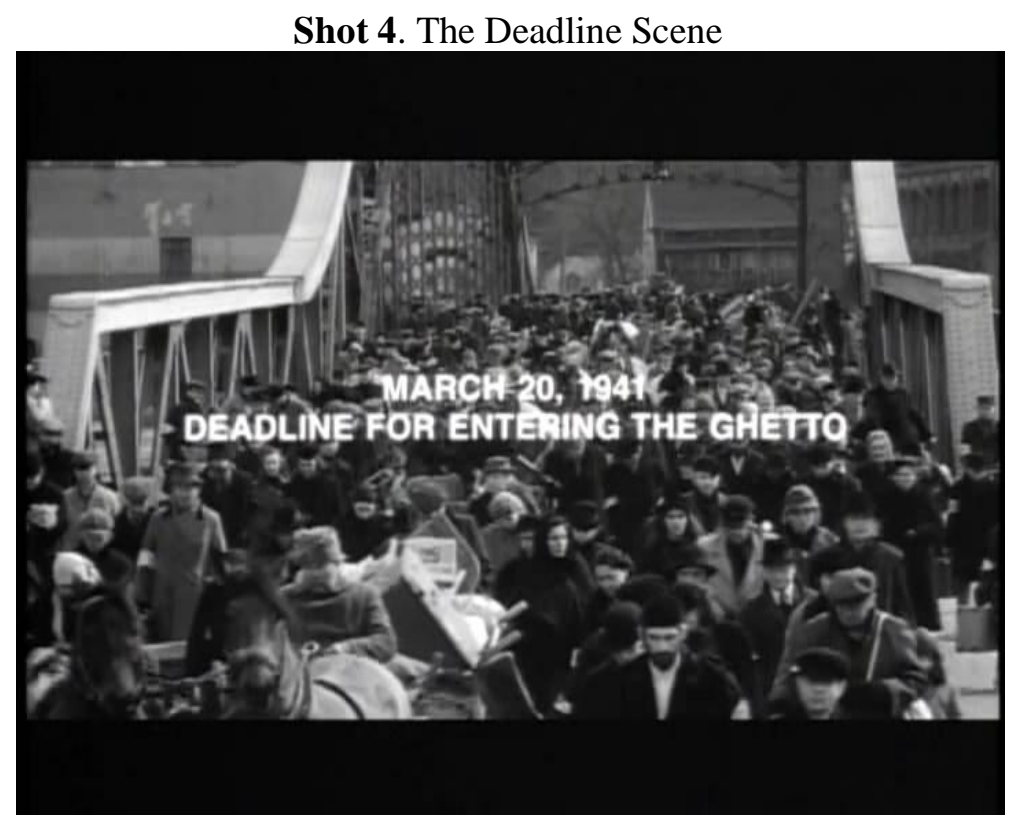

(5) March 20, 1941 Deadline for Entering the Ghett 


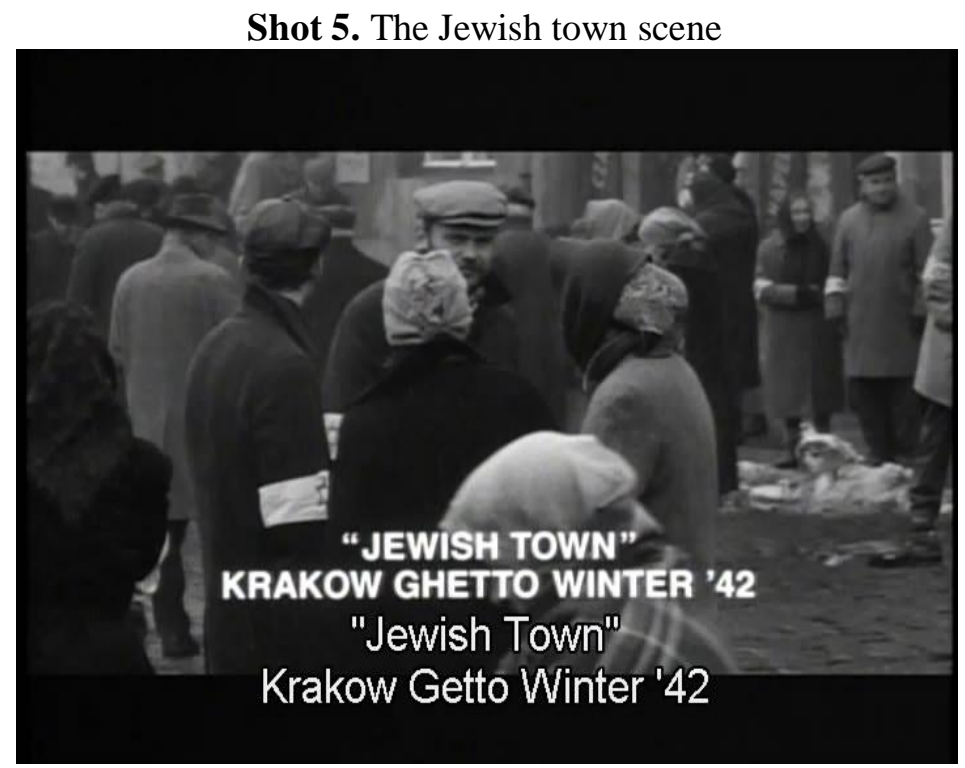

(6) "JEWISH TOWN" KRAKOW GHETTO WINTER'42

Shot 6. The Plaszow Forced Labor scene

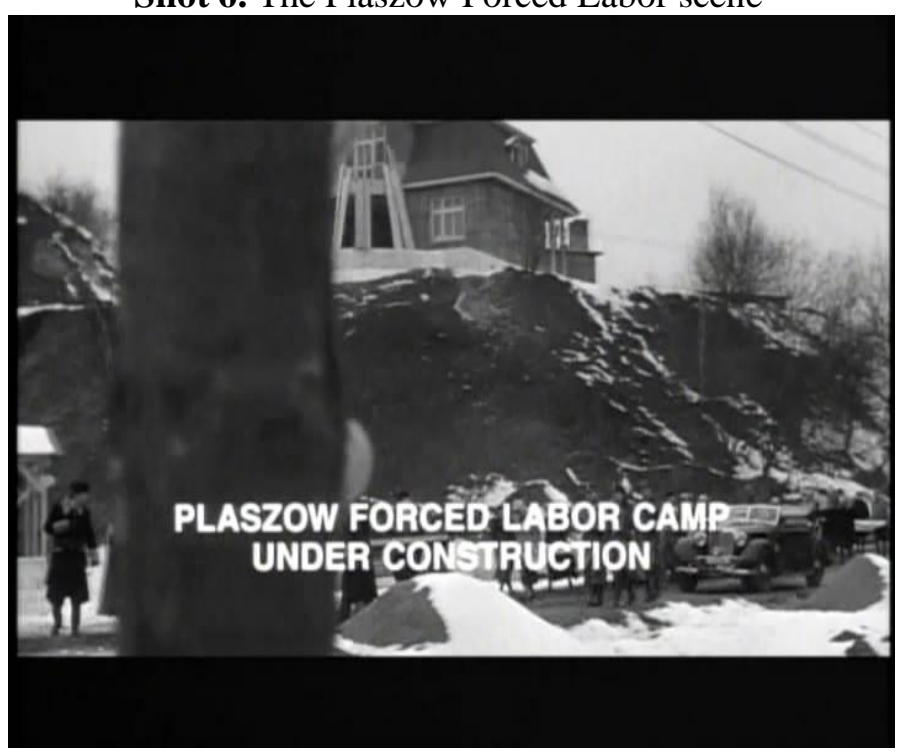

(7) Plaszow Forced Labor Camp Under Construction

These three intertitles indicating places and time imply that the places and the time $(4,5$, 6) are real. Thus, these legitimate the story of the film was real, natural, as the places were there and so did the time when the forced labor camp took place. These use naturalization legitimation which is frequently found in documentary-like films. The process used is existential process, where only the existents are left. So are the names below. These three names (8) are the existents. Like other naturalization legitimation, the following names also strengthen the story. 
Shot 7. Amon Goeth Introduction Scene (source: https://youtube.com)

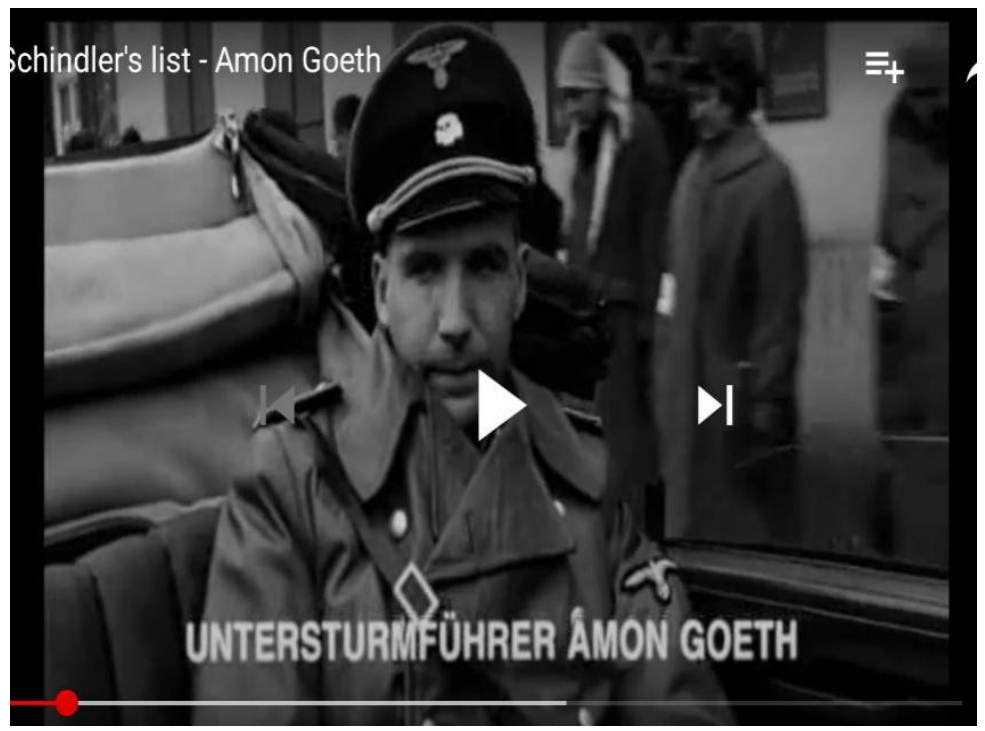

(8) OSKAR SCHINDLER Danka Dresner Amon Goeth

The intertitle above (Plaszow forced labor camp) and below contains moral evaluation, especially evaluative adjectives 'forced' in 'forced labor camp'; 'closed' in 'a closed Jewish district south..'; 'walled' in 'the walled Ghetto' and 'compulsory'. 'These adjectives link to specific discourses of moral values and these values are hinted at those derived from the interpretation at conscious level" (van Leeuwen, 2008: 110). In this way, those places are described having those, I may say, values which seem to make viewers' hearts moved (tear jerker).

(9) ... a closed Jewish district south of the Vistula River. Residency in the walled Ghetto is compulsory

Shot 8. The four thousand Jews left alive scene

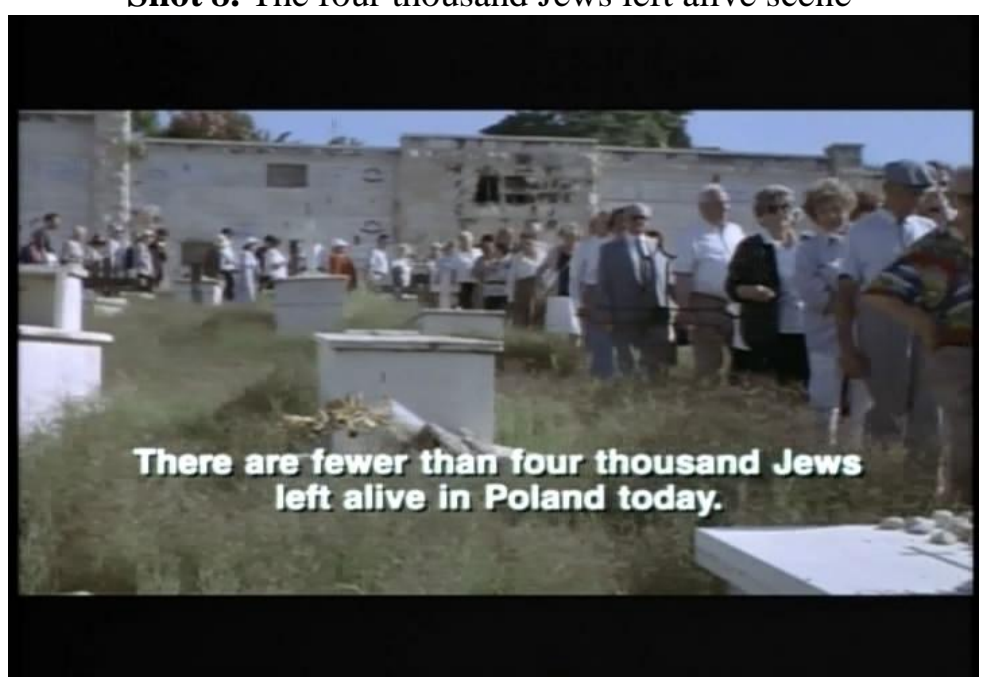

(10) There are fewer than four thousand Jews left alive in Poland today 


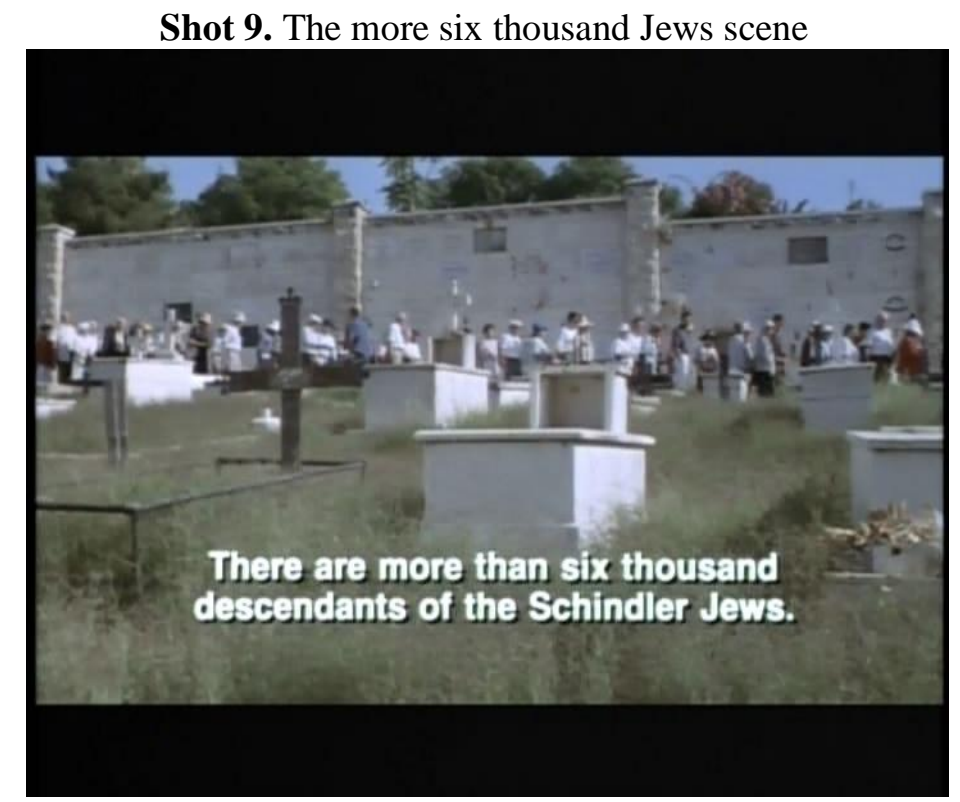

(11) There are more than six thousand Descendants of the Schindler Jews

These intertitles contain theoretical rationalization, in particular definition. I may consider this as definition, since they define what they are (the objectified entities) by describing them with existential process. 'Six thousand' and 'four thousand' signify the attribute the subject (the existent) possess. Therefore, these have propositions that four thousand Jews left alive in Poland (the setting where film story took place) and six thousand descendants of Jews saved by Schindler are still live 'today'. I suggest these numberings imply more valid data than no numberings. Also, these validate a notion that Jews killings and Jews saved by Schindler indeed exist.

\subsubsection{Hegemony works on the interplay of the multimodes}

The following is the table of the recapitulation of the analysis of five selected shots containing concrete quality of objects.

Table 1. The recapitulation of selected shots analyses

\begin{tabular}{|c|c|c|}
\hline Shot no. & Selected Visual Elements & Intersemiotic network \\
\hline (4) & $\begin{array}{l}\text { Camera Distance: Long Shot } \\
\text { Camera Angle: High Level } \\
\text { Color: Monochrome } \\
\text { Spatial: Center }\end{array}$ & Elaboration: exposition \\
\hline (5) & $\begin{array}{l}\text { Camera Distance: medium Long Shot } \\
\text { Camera Angle: High Level } \\
\text { Color: Monochrome } \\
\text { Spatial: Bottom }\end{array}$ & Elaboration: exposition \\
\hline (6) & $\begin{array}{l}\text { Camera Distance: Long Shot } \\
\text { Camera Angle: Eye Level } \\
\text { Color: Monochrome } \\
\text { Spatial: Bottom }\end{array}$ & Elaboration: exposition \\
\hline (7) & $\begin{array}{l}\text { Camera Distance: Medium Close Shot } \\
\text { Camera Angle: high Level } \\
\text { Color: Monochrome } \\
\text { Spatial: Bottom }\end{array}$ & Elaboration: exemplification \\
\hline
\end{tabular}


Table 1, cont.

\begin{tabular}{|c|l|l|}
\hline$(8)$ & Camera Distance: Long Shot & Elaboration: exposition \\
& Camera Angle: & \\
& Low Level & \\
Color: Multicolor & Spatial: Bottom & \\
\hline$(9)$ & Camera Distance: Long Shot & Elaboration: exposition \\
& Camera Angle: & \\
& Low Level & \\
& Color: Multicolor & \\
& Spatial: Bottom & \\
\hline
\end{tabular}

The five shots out of six are all signifying elaboration that is exposition type. This type means that the images are not exactly explaining the linguistic elements. Both the images and texts are in different ways of expressions. I think this is done because the filmmaker widens the viewers' interpretation, enabling those synthesizing messages behind those different images and the texts. The camera angle as well as the camera distance places concepts that there are some subjects together with environments described, and in some ways the figures in the images are described as weak (when the camera looks down) and as reality when the camera using eye level angle. The monochrome and multicolored frames are just explained previously, they also can construct cinematic magic. The text is sometimes put in the center and sometimes at the bottom, meaning that they are prominent, and the latter indicates reality. Shot 7 has distinctive features compared to those of the other five shots, they are: medium close shot which is good for conversation of two persons by Chandler (in Setiarini, 2012: 33) and "the intersemiotic relation constructed is elaboration: exemplification, using examples to explain the related media further" (Roehrich, 2013: 22).

\subsection{Hegemony reproduced in the availability of concrete quality of actions 3.3.1 Hegemony works on its linguistic elements}

Hegemony is also implemented through the concrete quality of actions. The quality of action is shown in the use of verbal process "he (Schindler: verbiage) was declared a righteous person by the YadVashem in Jerusalem (sayer)" and the other verbal process "invited'. The legitimation categories used comprise: Instrumental rationalization that is effect orientation, seen in 'to plant a tree' and 'to crowd into..' and naturalization rationalization observed through the availability of the names of places and the rest is moral evaluation hidden in the word 'only' which alludes the interpretation of the discourse maker. This shows that the maker puts his/her thought in describing how the place looks like, only through adverb he/she uses. 
Shot 10. Schindler was awarded scene

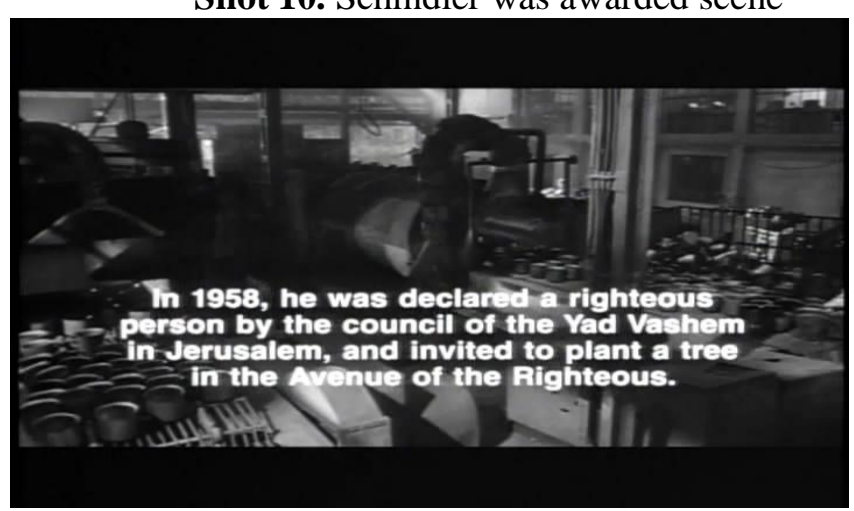

(12) In 1958, he was declared a righteous Person by the council of the Yad Vashem in Jerusalem, and invited to plant a tree in the Avenue of the Righteous.

(13) ...to crowd into an area of only sixteen square blocks

Shot 11. Schindler Jews grow scene

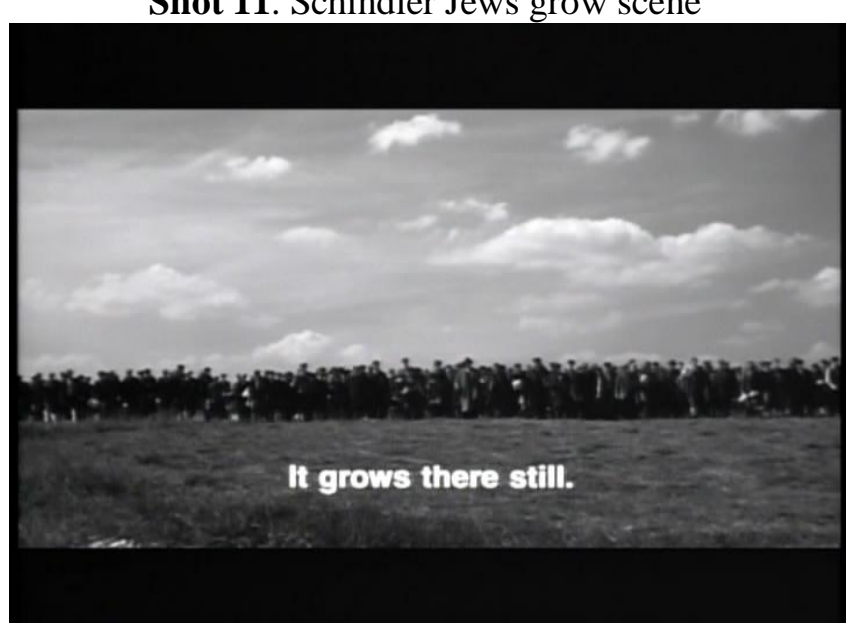

(14) It grows there still.

Apart from verbal process found in the proposition to provide viewers that the actions depicted as of reality, the material process 'grows' in 'it grows there still' can be an effective one to describe the action as real as possible. I do not intend to say that the notions in this film is manipulative, rather I would like to discover that this film can successfully convince viewers with their selected semiotic resources used, both the linguistic and visual elements. This material process then followed by 'the Schindler Jews today' which seem to be independent and it is, as it is so prominent. But, actually this is the Actor of the material process, creating an effect that this one is one stand alone, one salience entity. 


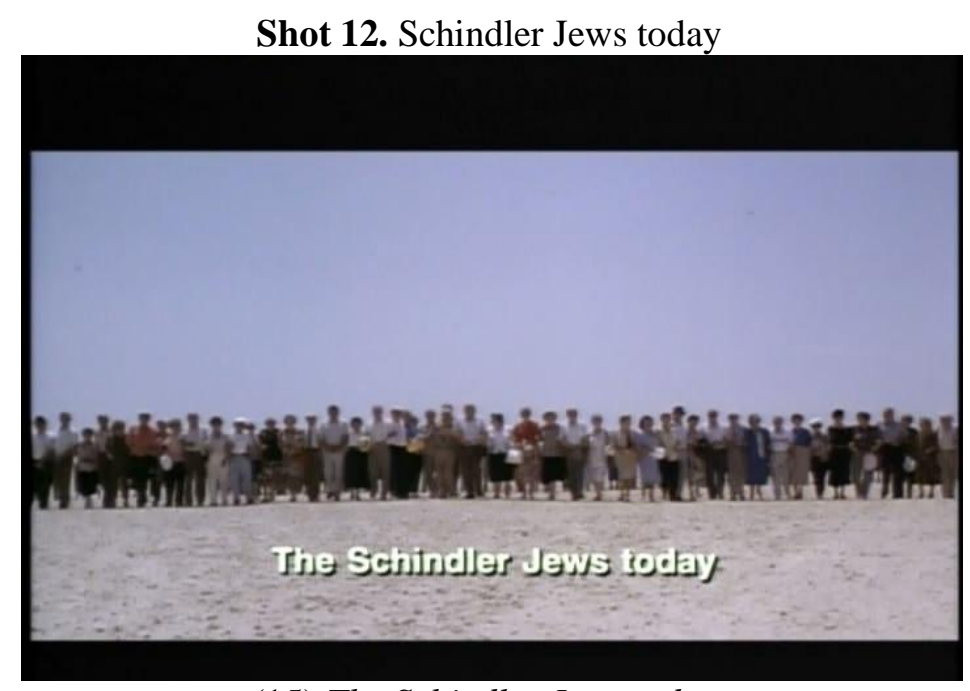

(15) The Schindler Jews today.

\subsubsection{Hegemony works on the interplay of its multimodes}

Shot 10 cannot directly describe the text mentioning Schindler's awarding as no 'direct' connection between the text and the image. The image is a fabric where Schindler run his business with his Jew labors, or I may call them Jew survivors, while the text is about Schindler was bestowed a reward for his good deeds. Clearly they are not related each other. That is why the category used is elaboration: exposition, where another term is used to represent another entity. The text is put at the bottom to show a reality. The camera angle taken is high level, to serve the subject as harmless entity and the camera distance used is long shot, meaning that this type shows the subject in an environment. Shot 11 and 12 extend the meanings by adding information about how the process takes place, with 'dramatic' elements (Roehrich, 2013: 27-28). In this way, the texts (14) 'it grows there still' and (15) 'The Schindler Jews today' are represented through pictures of thousands of Jews survivors walk hand in hand altogether in treeless field and displayed in two different colors (monochrome and multicolor). These mean the picture meanings go beyond what is seen: the treeless field symbolizes freedom, the blue sky means harmony. Chandler stated the extreme long shot signifies the atmosphere of the film and the eye level angle displays reality (in Setiarini, 2012). The texts are positioned at the bottom, showing something as real.

\subsection{Hegemony negotiated in the serve of punishments and rewards}

\subsubsection{Hegemony works on the linguistic elements}

Punishment and rewards in all their types are presumably the logic behind many children stories, where good persons will soon get their rewards and bad persons finally end with bad luck or even worse, a misery. This logic is also used in this film, when the filmmaker released two types of different characters: Oskar Schindler and Amon Goeth. Schindler is represented as the good person whereas Goeth is the villain. The linguistic elements show implied meanings: first, the verbal process containing information that Schindler was given an award of the righteous person from the Jew Council in Jerusalem. The legitimation works on its notion to give reward the protagonists through the moral tale; and, cautionary tale is applied to implant a meaning that Goeth, the villain, deserved his bad attitude. Goeth was described as Goal when Department (Nazi) did a material process 'orders' to do another concrete yet brutal material process done by Goeth. In this way, this negative actuality showing them as a powerful entity makes the world look a more dangerous place (Butt, et al, 2004: 274). These are then followed by a notion that Goeth was also a goal of another accepted yet terrifying material process 'arrested' and 'hanged' done by legitimated institution (not clearly mentioned) and this indicate that the antagonist at the end get what he should get as a punishment for bad things he did in the past. Another legitimation 
category at the same time is also implemented, that is, moral evaluation used, in particular comparison: positive and negative. These two entities are compared: Schindler and Goeth.

(16) In 1958, he was declared a righteous Person by the council of the Yad Vashem in Jerusalem, and invited to plant a tree in the Avenue of the Righteous.

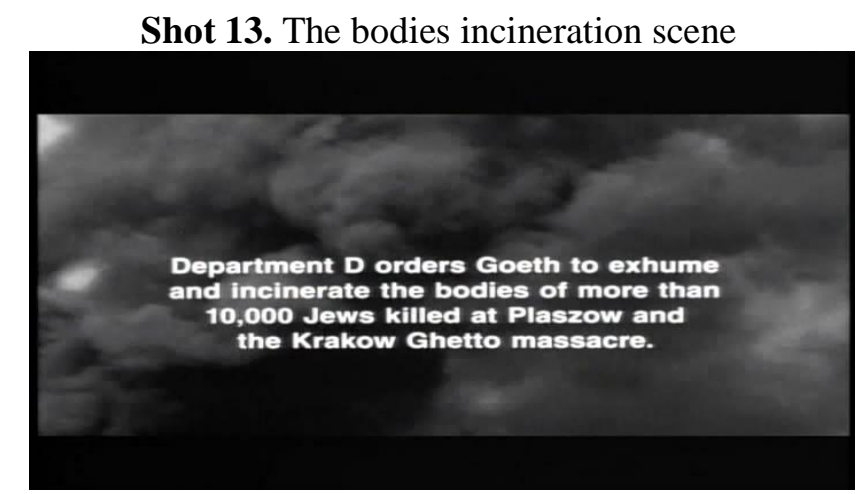

(17) Department Dorders Goeth to exhume and incinerate the bodies of more than 10,000 Jews killed at Plaszow and the Krakow Ghetto massacre.

Shot 14. Goeth hanging scene (source: https://youtube.com)

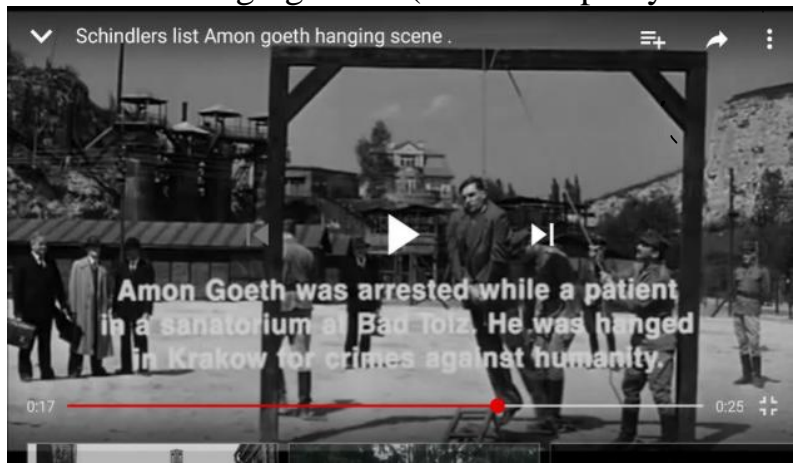

(18) Amon Goeth was arrested while a patient in a sanatorium at Bad Tolz. He was hanged in Krakow for crimes against humanity.

\subsubsection{Hegemony works on the interplay of the multimodes}

The texts containing that Goeth are one to blame for the mass killings and Goeth's punishment are extended in shot 13 and 14. These two shots are really dramatic, as Roehrich (2013: 28) stated "in relation to enhancement: manner type". The long shot camera angle shows the subject and the environment are connected. The heavy dark smoke in shot 13 visualizes the action Goeth did, incinerating the dead bodies of Jews victims, so is shot 14 where Goeth was visualized to be hanged in front of the public pertaining the text, he was hanged for crimes he did. The eye level disables viewers to interpret them, instead they will accept them as reality.

\section{Conclusion}

The distribution of power of the dominant class is not always evident, rather in some ways it looks natural. This dominant class is believed to be the capitalist society, represented by American, which does some hegemonic strategies, one of which is ideological legitimating. This legitimation is reached through commonsense implantation toward the marginal class (viewers), expected to share the same concepts build in the meaning-making media the dominant class uses. One of them is films. Condit (in Kperogi, 2013: 323) stated films contain values inscribed in the mass-mediated discourse through the process of opinion formation and accretion. Gonzales explained that, however, they are not acted as a direct stimulation of thought but a framing of competing definitions of reality (in Kperogi, 2013: 324). This opaque entity -hegemony - needs a 
technique to decipher the selected semiotic resources it uses. Therefore, to find out how hegemony exists in a discourse, van Leeuwen (2008) show us the ways. He (2008: 105-123) said that there are four types of legitimation major categories: authorization; moral evaluation; rationalization; and, mythopoesis. It is found that the legitimation applied is more like one concerning with non-personal authority, moral evaluation, especially naturalization showing names of places, time and names of persons, experiential, definition as well as effect orientation of both instrumental and theoretical evaluations also applied and mythopoesis, both moral and cautionary tales, existing there. The chosen visual elements, like camera angle, camera distance, color and spatial information are mostly dealing with eye level, and high level angle, extreme, medium long shots, long shot and medium close shot distance, colors mostly cover monochrome and the rest are multicolor; and the spatial information used are mostly at the middle and bottom. These all cooperate one another through some relationships: enhancement (temporal, spatial and manner); elaboration (exposition, exemplification and clarification). They do construct commonsense which I may conclude that this deals with values accepted by most people. The linguistic elements applying material, relational and existential processes imply concrete quality, values and objectivity, so do the visual elements which mostly signify reality, values and context-bound concept. In brief, they work to build a concrete quality of objects, a concrete quality of action, and punishment and rewards to construct the hegemony.

\section{References}

Media hegemony. Available at www.researchgate.et/publication/275408880. (Accesed on June 5, 2018 at 2.01 p.m.).

Bloor, T., \& Bloor, M. 1995. The functional analysis of English: a hallidayan approach. New York: Oxford University Press.

Chandler, D. 2002. Semiotics: the Basics. New York: Routledge.

Halliday, M. A. K. \& Hassan, R. 1985. Language, context, and text: aspects of language in a social-semiotic perspective. Victoria: Deakin University Press.

Halliday, M. A. K., \& Matthiessen, C.M. I. M. 2004. An introduction to functional grammar. New York: Oxford University Press.

Joseph, J. 2002. Hegemony: a realist analysis. New York: Routledge.

Kress, G. 2010. Multimodality: a social semiotic approach to contemporary communication. New York: Routledge.

Kperogi, F. A. 2011. Cooperation with the corporation? CNN and the hegemonic cooptation of citizen journalism through iReport.com. New media and society: mms.sagepub.com

Lacey, N. 1998. Image and representation: key concepts in media studies. New York: St Martin's Press Inc.

Levorato, A. 2003. Language and gender in the fairy tale tradition: a linguistic analysis of old and new story telling. New York: Palgrave MacMillan.

Machin, D., \& van Leeuwen, T. 2007. Global media discourse: a critical introduction. New York: Routledge.

O’Halloran, K. L. 2004. Visual semiosis in film. In O’Halloran, K. L (ed.). Multimodal discourse analysis. London: Continuum, p 109-130.

Roehrich, L. W. 2013. A word is worth a thousand picture: a systemic functional and multimodal discourse analysis of intersemiotic evaluation in university science textbooks. Marshall Digital Scholar.

Setiarini, R. 2012. Six concepts of holocaust in schindler's list (a study of semiotics). Yogyakarta: Interpena.

Films \& cultural hegemony: American hegemony "outside" and "inside" the "007" movie series. Available at www.questia.com/library/1P3-1995206011/. (Accessed on June 5, 2018).

Clip joint: films that use both black and white and color. Available at the guardian.com (Accessed on June 8, 2018 at 10.35 p.m.). 
Van Dijk, T. 2004. Political discourse and political cognition. In Chilton, P \& Schaffner, C. (ed.). Politics as text and talk: analytic approaches to political discourse. Amsterdam: John Benjamins Publishing Company, p. 204.

Van Leeuwen, T. 2008. Discourse and practice: new tools for critical discourse analysis. Oxford: Oxford University Press.

Ventola, E., \& Guijarro, A. J. M. 2009. The world told and the world shown. London: Palgrave McMillan.

www.youtube.com 